\title{
New insights into testicular granulosa cell tumors (Review)
}

\author{
XIN FANG and QINGLEI LI \\ Department of Veterinary Integrative Biosciences, College of Veterinary Medicine and \\ Biomedical Sciences, Texas A\&M University, College Station, TX 77843, USA
}

Received May 12, 2020; Accepted August 26, 2020

DOI: $10.3892 / \mathrm{ol} .2020 .12156$

\begin{abstract}
Testicular granulosa cell tumors (TGCTs) are rare tumors of sex cord-stromal origin. TGCTs are mostly benign and can be classified into the adult type and the juvenile type. Due to the rarity of clinical cases and limited research efforts, the mechanism underpinning the development of TGCTs remains poorly understood. A landmark study has identified a forkhead box L2 mutation $(\mathrm{C} 134 \mathrm{~W})$ in nearly all adult ovarian GCTs, but its implications in TGCTs are unclear. The present study focuses on reviewing the major signaling pathways (e.g., the transforming growth factor $\beta$ signaling pathway) critical for the development of TGCTs, as revealed by genetically modified mouse models, with a goal of providing new insights into the pathogenesis of TGCTs and offering directions for future studies in this area. We posit that a comparative approach between testicular and ovarian GCTs is valuable, as granulosa cells and Sertoli cells arise from the same progenitor cells during gonadal development. Developing pre-clinical mouse models that recapitulate TGCTs will help answer the remaining questions around this type of rare tumor.
\end{abstract}

\section{Contents}

1. Introduction

2. Tumors in the testes

3. TGCTs: Subtypes and histopathology

4. FOXL2 mutation in GCT development

5. Genetically modified mouse models to study TGCTs

6. Concluding remarks and future directions

Correspondence to: Dr Qinglei Li, Department of Veterinary Integrative Biosciences, College of Veterinary Medicine and Biomedical Sciences, Texas A\&M University, 588 Raymond Stotzer Parkway, College Station, TX 77843, USA

E-mail: qli@cvm.tamu.edu

Key words: testicular granulosa cell tumor, mouse models, signaling pathways, transforming growth factor $\beta$

\section{Introduction}

Granulosa cell tumors (GCTs) comprise granulosa cells and stromal components (1). GCTs are generally low-grade malignancies, manifested by indolent growth and a low risk of metastasis (1). However, the prognosis of GCTs is stage-dependent, and patients at advanced tumor stages tend to have a higher risk of recurrence (2), making long-term surveillance necessary. The recurrence also increases the mortality rate and the economic/emotional burden of the patients. Thus, it is critical to understand the molecular mechanism of GCT development and identify predictors for tumor recurrence and optimal regimen for tumor treatment.

Ovarian GCTs are the major type of malignant sex cord-stromal tumors (3). There are two subtypes of ovarian GCTs, namely the adult type and the juvenile type (4). It has been reported that $>80 \%$ of girls $<8$ years of age with juvenile-type GCTs demonstrate precocious pseudopuberty (5). By contrast, adult-type GCTs often occur in perimenopausal women, with an unpredictable outcome of relapse. The development of adult-type GCTs is often accompanied by symptoms of hormone dysregulation (e.g., amenorrhea, uterine bleeding and endometrial hyperplasia) (6,7). The clinical symptoms, diagnostic imaging, histology of surgery-obtained tumor samples and presence of tumor markers [e.g., inhibins and anti-Mullerian hormone (AMH)] provide useful information for the diagnosis of GCTs $(8,9)$.

GCTs can also occur in the testis. Similar to ovarian GCTs, testicular GCTs (TGCTs) contain the adult and the juvenile subtypes. While ovarian GCTs account for $290 \%$ of ovarian sex cord-stromal tumors (reported in 2012) (4), the adult or juvenile type of TGCTs accounts for $<0.5 \%$ of testicular sex cord-stromal tumors (reported in 2017) (10). Although similarities exist between GCTs in the testis and the ovary $(11,12)$, mechanisms underlying the development of these tumors remain poorly characterized, partially owing to the rarity of this type of testicular malignancy. In the present review, the subtypes and pathology of TGCTs and important signaling pathways associated with tumorigenesis are discussed. The study delves into forkhead box L2 (FOXL2)-related signaling, wingless-related MMTV integration site (WNT)/ $\beta$-Catenin (CTNNB1) signaling, the phosphoinositide 3-kinase (PI3K) pathway and the transforming growth factor $\beta$ (TGF $\beta$ ) pathway in the development of TGCTs. With the development of new mouse models that focus on TGCTs, it is anticipated that the pace of investigation 
into the molecular and genetic basis of these tumors will be accelerated.

\section{Tumors in the testes}

Testicular tumors occur mostly in males of 14-44 years old (13). Based on the 2016 classification by the World Health Organization, testicular tumors contain germ cell tumors of two groups [i.e., tumors derived from germ cells neoplasia in situ (GCNIS) and those unrelated to GCNIS], as well as sex cord-stromal tumors and several other types (14). Germ cell tumors account for the majority of testicular tumors. Sex cord-stromal tumors make up $4 \%$ of tumors in the testis (15) and consist of Leydig cell tumors, Sertoli cell tumors, GCTs, fibroma and thecoma group tumors, mixed-type tumors and unclassified tumors (14). Leydig cell tumors are the most common type of sex cord-stromal tumors. These tumors are often well circumscribed and appear brown, yellow or gray-white in color on the cut surface (16). The cell types in a given Leydig cell tumor may be variable. Histologically, the cells are often medium to large in size and polygonal in shape, with eosinophilic granular cytoplasm $(16,17)$. Due to the histological and immunohistochemical similarities between GCTs in females and males $(11,12)$, a comparative approach is likely to be valuable in gaining mechanistic insights into tumorigenesis and discovering common regulatory pathways. As the causes and pathogenesis of these rare testicular tumors are poorly defined, clinically relevant mouse models are particularly useful in this research field to determine the oncogenic insult and potential therapeutic targets $(12,18,19)$.

\section{TGCTs: Subtypes and histopathology}

TGCTs can be divided into the juvenile type and the adult type (Table I). Juvenile-type TGCT is a more common form compared with adult-type TGCT. The juvenile type represents the most common tumors in the male gonad in patients $<6$ months of age and can even be diagnosed shortly after birth due to the increased size of the testis (20). Histologically, follicular components are present in juvenile-type TGCTs $(10,20)$. Tumor cells have round dense nuclei with infrequent nuclear grooves, and abundant mitosis can be found (21). The juvenile-type tumors are generally benign, with rarely observed metastasis. In a report of 70 cases, only 2 cases showed lymphovascular invasion and 4 cases exhibited rete testis involvement (21). The juvenile-type TGCTs were reported to be positively stained for FOXL2, steroidogenic factor-1 and vimentin (21). Some tumors also express inhibin, calretinin, Wilms tumor 1 and SRY-box transcription factor 9 (SOX9) (21). As inhibin is expressed by both granulosa cells and Sertoli cells, it is unclear whether the variable expression of the inhibin observed in juvenile TGCTs is stage-dependent or merely reflects the individual variation of these tumors.

Some studies have suggested that the formation of granulosa cell tumors is associated with sex chromosome abnormalities and aberrant gonadal development $(22,23)$. It has been shown that infants with mixed gonadal dysgenesis or intersexual disorder develop juvenile-type GCTs (23). Another example of this link was found in the case of a newborn baby with the $\mathrm{X} / \mathrm{XY}$ karyotype who developed congenital juvenile-type
TGCT (22). The levels of inhibin B, $\beta$-hCG and testosterone appear normal in some juvenile-type GCT patients (20). High levels of serum $\alpha$-fetoprotein (AFP) are observed in some juvenile-type TGCTs $(20,21)$; however, AFP levels are physiologically high in infants and newborns (24).

Adult-type TGCTs are extremely rare, with 91 cases described to date (25). Microscopically, the tumor cells have vague cell borders and pale nuclei containing nuclear grooves $(10,26)$. The tumor cells are less mitotic compared with those of juvenile-type GCTs (10). It is notable that juvenile-type TGCTs lack Call-Exner bodies (i.e., small eosinophilic fluid-filled spaces within microfollicular structures) that are observed in the adult-type TGCTs (10). Although most adult-type TGCTs are benign, the metastatic potential of these tumors remains of concern. For instance, in a previous study, one patient was found to develop metastases 10 years after the first diagnosis, while additional metastasis was found in the inguinal lymph node of another patient 1 year after the diagnosis and detection of retroperitoneal lymph node metastasis (27). In another case, metastasis was found in the bone of a patient 6 years after orchidectomy surgery (28). Thus, long-term follow-up/monitoring is needed for patients with TGCTs. Histopathologically, the adult-type GCTs are identified as solid and/or cystic tumors (10). Laterality has been reported in most documented adult-type GCT cases in males (25). The histological/pathological criteria or clinical features that predict the malignant/benign disposition of TGCTs are not well defined. It appears that tumor size $(>5 \mathrm{~cm})$, but not mitotic count, tumor necrosis or other parameters, is positively associated with the malignancy of adult-type TGCTs (29). Orchidectomy and testis-sparing surgery have been used to treat TGCTs (25). Currently, it remains unclear with regard to the genetic or molecular determinants that contribute to the phenotypic and prognostic outcomes of the juvenile-type versus the adult-type TGCTs. Answering this question may help develop tailored treatment options for the two subtypes of TGCTs.

\section{FOXL2 mutation in GCT development}

FOXL2, a granulosa cell-expressed gene, regulates granulosa cell fate and ovarian function (30). Supporting a critical role of Foxl2 as a female gene, disruption of FOXL2 in adult ovaries induces the expression of SOX9 specific to the male gonad (31). FOXL2 is expressed in juvenile-type TGCTs (32). Notably, the expression of SOX9 is found in the cytoplasm of FOXL2-positive cells in some juvenile-type TGCTs (32). As FOXL2 is a granulosa cell lineage marker, this finding suggests potential Sertoli cell-granulosa cell transdifferentiation during the formation of TGCTs (32).

A missense mutation of FOXL2 [nt. 402C $>\mathrm{G}(\mathrm{C} 134 \mathrm{~W})$ ] is vital in the pathogenesis of adult-type ovarian GCTs (33). With regard to its contribution to GCT development, studies have shown that this mutation impairs the capability of growth differentiation factor 9 , an oocyte-produced protein, in promoting follistatin transcription in the presence of SMAD3 (34). This may lead to increased cell proliferation due to unopposed activin signaling $(34,35)$. In addition, FOXL2 mutation also reduces apoptosis and increases the induction of aromatase (CYP19), which promotes estrogen 
Table I. Differences between the TGCT subtypes.

\begin{tabular}{lll}
\hline TGCT-related features & \multicolumn{1}{c}{ Juvenile-type TGCTs } & \multicolumn{1}{c}{ Adult-type TGCTs } \\
\hline Age & $\begin{array}{l}\text { Most common tumors in the } \\
\text { testis at <6 months of age }\end{array}$ & Median age, 44 years (range, 12-87 years) \\
Metastasis & $\begin{array}{l}\text { Rare } \\
\text { Yellow to tan-white cut }\end{array}$ & $\begin{array}{l}\text { Metastatic potential } \\
\text { Yacroscopic feature }\end{array}$ \\
Microscopic feature & $\begin{array}{l}\text { Round dense nuclei; infrequent } \\
\text { nuclear grooves; abundant mitosis }\end{array}$ & $\begin{array}{l}\text { Vague cell borders; pale nuclei with nuclear } \\
\text { grooves; Call-Exner bodies }\end{array}$ \\
Genomics/genetics & $\begin{array}{l}\text { Abnormal sex chromosome and } \\
\text { gonadal development }\end{array}$ & $\begin{array}{l}\text { Some tumors contain the FOXL2 mutation } \\
\text { (10,21) }\end{array}$ \\
& &
\end{tabular}

TGCT, testicular granulosa cell tumor; FOXL2, forkhead box L2.

synthesis (36-38). Lima et al (39) identified a FOXL2 mutation in adult-type TGCTs, with a lower mutation frequency compared with that in ovarian GCTs. However, this mutation was not found by the same researchers in other testicular tumors such as juvenile-type TGCTs and Sertoli-Leydig cell tumors, likely due to the limited number of cases examined and/or the low mutation frequency or lack of mutation in those tumors (39). Thus, mutational analysis of FOXL2 may prove beneficial in the differential diagnosis of the two subtypes of TGCTs if they demonstrate a different profile of FOXL2 mutation. Moreover, an in-depth understanding of the potential pathogenic function of the FOXL2 mutation in TGCTs will be instrumental for developing tailored treatment modalities.

\section{Genetically modified mouse models to study TGCTs}

Elegant reviews on molecular pathogenesis, signaling pathways and mouse models of ovarian GCTs have been published $(4,40,41)$. The present review focuses on several mouse models that have been reported to develop testicular tumors with a sex cord-stromal origin $(12,18,19,42-44)$. Inhibins and activins are key regulators of ovarian development and function. In the ovary, inhibins are mainly synthesized by granulosa cells and negatively regulate the secretion of follicle-stimulating hormone (FSH) (45). In the male gonad, Sertoli cells produce inhibins that regulate the testicular function (46). Inhibin $\alpha$ (Inha)-knockout mice develop sex cord-stromal tumors in both sexes (42). The neoplasms are mixed or incompletely differentiated tumors, accompanied by increased serum FSH levels (42). Deletion of both Inha and gonadotropin-releasing hormone inhibits tumor development and reduces the levels of FSH and luteinizing hormone (47). CDKN1B (also known as p27) is a cyclin-dependent kinase inhibitor that suppresses $G_{1}$ phase progression. Compound deletion of $C d k n l b$ and Inha accelerates the development of testicular tumors in males compared with deletion of Inha alone (48). Deletion of another regulator of the $\mathrm{G}_{1} / \mathrm{S}$ transition, cyclin D2, inhibits tumor progression in Inha null mice (49). Loss of inhibins potentiates the activin signaling. It has been found that SMAD3 acts as an essential mediator of the unopposed activin signaling in testicular tumor development induced by Inha deletion (50). A sexually dimorphic function has been observed for SMAD3 in gonadal tumor development induced by the loss of inhibins, where depletion of SMAD3 has a more pronounced protective effect on tumorigenesis in the male compared with that in the female (50).

WNT/CTNNB1 and PI3K/AKT signaling pathways play important roles in regulating the development of multiple types of cancer (51-54). In the female, dysregulation of CTNNB1 signaling triggers the formation of ovarian GCTs (52). Male mice bearing conditional expression of a stable CTNNB1 mutant and deletion of phosphatase and tensin homolog (Pten) using AMH type 2 receptor (Amhr2)-cyclization recombination (Cre) develop TGCTs at an early age, with lung metastases in nearly half of the mice by 4 months (18). These tumors express Wnt4 and FOXL2 (18). The mechanism underlying tumor development in this mouse model remains unclear. A loss of PTEN enhances PI3K/AKT signaling activity and promotes the phosphorylation of FOXO1A (18); however, the role of FOXO1A in tumorigenesis awaits further elucidation. Notably, it was recently found that the conditional overactivation of CTNNB1 in mouse Sertoli cells using Amh-Cre through elimination of a Ctnnbl exon required for CTNNB1 protein degradation induces transdifferentiation of Sertoli cells into granulosa-like cells and the formation of TGCTs (43). Mechanistically, activation of WNT signaling increases the expression of FOXL2 via the binding of CTNNB1 to the FOXL2 promotor at the T-cell factor/lymphoid enhancer factor binding sites (43). This finding may also partially explain how overactivation of CTNNB1 promotes the formation of TGCTs in the aforementioned mouse model containing simultaneous activation of WNT and PI3K/AKT signaling (18).

Kirsten rat sarcoma viral oncogene homolog (Kras) is an oncogene that encodes a small GTPase (55). Expression of KRAS $^{\mathrm{G} 12 \mathrm{D}}$ inhibits granulosa cell proliferation and differentiation in early ovarian follicles, but slightly enhances cell proliferation in large antral follicles, revealing follicular stage-dependent roles of the KRAS mutant (56). Mouse models with oncogenic KRAS ${ }^{\mathrm{G} 12 \mathrm{D}}$ expression or PTEN ablation in conjunction with CTNNB1 overactivation using Amhr2-Cre or Cyp19-Cre have been created to determine interactions between WNT and PI3K/RAS signaling (19). It was found that constitutive activation of KRAS or loss of PTEN promotes the development of ovarian GCTs or TGCTs 


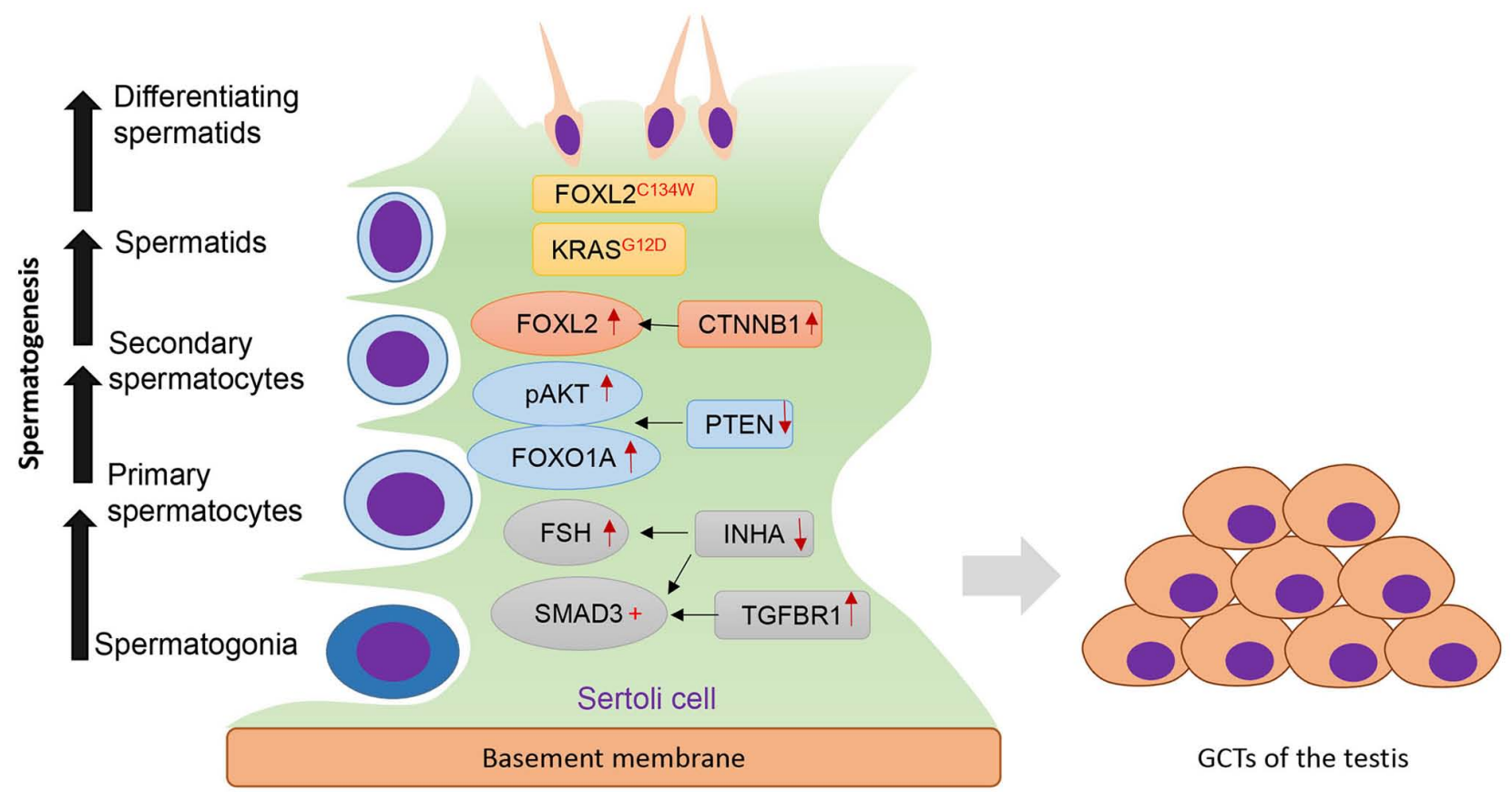

Figure 1. Key regulators of TGCT development. Sertoli cells serve an important role in maintaining normal spermatogenesis. Dysregulation of several genes/signaling pathways induces the formation of TGCTs. Increased TGF $\beta$ signaling via TGFBR1 activates SMAD3, whereas ablation of INHA increases FSH levels and enhances SMAD3 signaling. Loss of PTEN promotes pAKT and FOXO1A signaling. Activation of CTNNB1 results in increased expression of FOXL2. In addition, KRAS ${ }^{\mathrm{G} 12 \mathrm{D}}$ and FOXL2 mutation (FOXL2 $2^{\mathrm{C} 134 \mathrm{~W}}$ ) are also implicated in TGCT development. TGCT, testicular granulosa cell tumor; FOXL2, forkhead box L2; KRAS, Kirsten rat sarcoma viral oncogene homolog; CTNNB1, $\beta$-Catenin; PTEN, phosphatase and tensin homolog; FSH, follicle-stimulating hormone; INHA, inhibin $\alpha$; TGFBR1, TGF- $\beta$ receptor type-1; p, phosphorylated.

in stable CTNNB1-expressing mice (19). Consistent with the benign feature of TGCTs, metastasis was not found and the viability of mice was not compromised up to 8 months. As expected, these mice are infertile due to tumor development and impaired spermatogenesis (19).

Members of the FOX family are implicated in multiple developmental processes and diseases $(57,58)$. FOXL2 and FOXO3 play key roles in ovarian development and function (58). FOXO1 acts as a tumor suppressor through inhibiting CYP19 expression via mutant FOXL2 (C134W) and SMAD3 in the human non-luteinized granulosa cell line (59). In addition, $20 \%$ of Foxol/3 double conditional knockout mice in the ovary using Amhr2-Cre or Cyp19-Cre develop ovarian GCTs by 6-8 months (60). These tumors cause increased levels of inhibins and estradiol (60). It is yet unclear whether FOXO1/3 is involved in TGCT development.

TGF $\beta$ superfamily signaling is implicated in numerous physiological and pathological processes (61). TGF $\beta$ ligands signal through membrane-associated type II and I receptors (TGFBR2/TGFBR1) and activate receptor-regulated SMADs (R-SMADs), including SMAD2/3 (TGF $\beta /$ activin-responsive SMADs) and SMAD1/5/8 [bone morphogenetic protein (BMP)-responsive SMADs]. R-SMADs then complex with SMAD4 to elicit biological responses via the regulation of gene transcription (62). TGF $\beta$ signaling plays divergent roles in cancer development (63) and is important for GCT development (62). A study by Pangas et al (44) revealed a role of BMP signaling in GCT development by demonstrating that conditional deletion of Smadl and Smad5 promotes the development of GCTs in the ovary, but not in the testis. Instead, Sertoli-Leydig tumors form in Smad1/5 conditionally deleted males (44). In a continuum of research interrogating the role of TGF $\beta$ signaling in reproductive development and function, a mouse model has been generated with constitutively activated TGFBR1 (TGFBR1-CA) in the gonad $(12,64)$. Both male and female TGFBR1-CA mice develop GCTs $(12,64)$. TGCTs express granulosa cell markers [i.e., INHA, FOXO1 and FOXL2]. In addition, expression of CTNNB1 is increased in the testes of TGFBR1-CA mice (12), reinforcing a role of WNT/CTNNB1 signaling in GCT formation. The cellular origin of TGCTs remains enigmatic. In male TGFBR1-CA mice, constitutive activation of TGFBR 1 is induced by Amhr2-Cre, which is expressed in both Sertoli cells and Leydig cells (65-67). Notably, Sertoli cells and granulosa cells appear to arise from the same progenitor cells (68). Moreover, Sertoli cells with dysregulated gene expression can transdifferentiate into granulosa-like cells (43). Thus, it is conceivable that TGCTs in TGFBR1-CA males are derived from Sertoli cells. To determine the potential contribution of Sertoli cells to TGCT formation, the developmental dynamics of TGCTs were assessed by comprehensive histological and immunohistochemical analyses (12). It was found that tumors arise within seminiferous tubules, where the only somatic cell type is the Sertoli cell (12). Moreover, loss of doublesex and mab-3 related transcription factor 1 (a testis-determining protein), and gain of FOXL2 were found in seminiferous tubules enriched for Sertoli cells in TGFBR1-CA males (12). Studies are ongoing with regard to identifying the tumorigenic program in the testis that mediates the overactivation of TGF $\beta$ signaling.

Overall, several key genes and signaling pathways have been associated with TGCT development (Fig. 1). Although robust genetic evidence supports the phenotypic relevance 
A TGFBR1 ${ }^{\mathrm{CA}}: \mathrm{mTmG}$
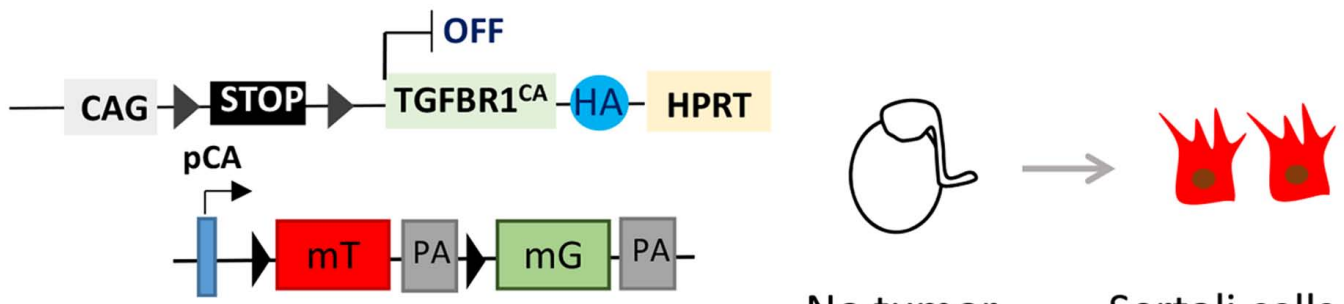

No tumor Sertoli cells

\section{B TGFBR1 ${ }^{\text {CA:mTmG:SC-Cre }}$}

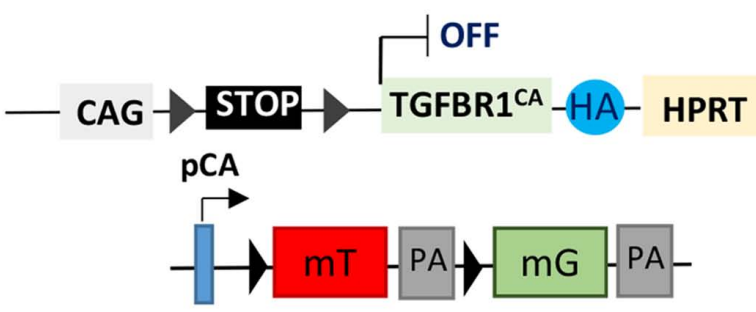

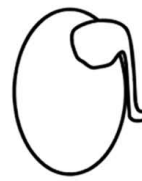

TGCT

SC-Cre

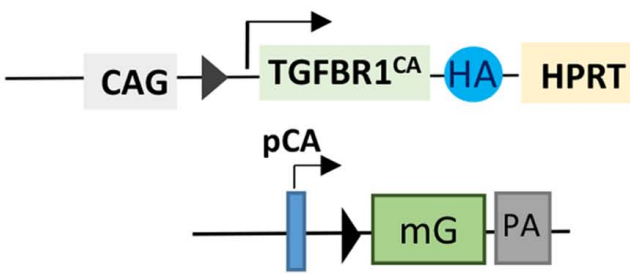

Figure 2. Proposed genetic labeling to trace TGCT origin in TGFBR1-CA mice. Mice harboring constitutively active TGFBR1 will be bred with mTmG mice and Sertoli cell-specific Cre mice. (A) Sertoli cells in the testes of control mice express tdTomato (red). (B) In the TGFBR1-CA:mTmG:SC-Cre testes, Sertoli cells express constitutively active TGFBR1 and EGFP (green). The experiment is expected to elucidate whether Sertoli cells contribute to the development of TGCTs and whether activation of TGFBR1 in Sertoli cells is sufficient to induce TGCTs. mT, membrane-targeted tdTomato; mG, membrane-targeted EGFP; PA, polyadenylation sequences; pCA, chicken $\beta$-actin promoter with CMV enhancer; CAG, human cytomegalovirus enhancer and chicken $\beta$-actin; HA, hemagglutinin; SC, Sertoli cell; TGCT, testicular granulosa cell tumor; TGFBR1, TGF- $\beta$ receptor type-1; HPRT, hypoxanthine guanine phosphoribosyl transferase.

of these mouse models to TGCTs, their potential utility for investigating the etiology and pathogenesis of TGCTs, as well as testing therapeutic agents, requires further evaluation.

\section{Concluding remarks and future directions}

TGCTs are rare tumors that remain enigmatic in numerous aspects. To better define tumor etiology and discover early diagnostic and therapeutic options, it is beneficial to develop pre-clinical mouse models that recapitulate TGCTs. To unambiguously define the origin of TGCTs in the TGFBR1-CA mouse model (12), it is necessary to specifically activate TGFBR1 using a Cre driver specific to Sertoli cells (Fig. 2). It is anticipated that sustained activation of TGFBR1 in Sertoli cells (TGFBR1-CA ${ }^{S C}$ ) will induce TGCT development (Fig. 2). Our future genetic labeling experiments using a dual fluorescence reporter mouse line, membrane-targeted tdTomato $(\mathrm{mT}) /$ membrane-targeted EGFP (mG) (69), may elucidate tumor cell origin. In the $\mathrm{mT} / \mathrm{mG}$ mouse, Cre-negative cells express tdTomato, a red fluorescent protein (69) (Fig. 2A). By contrast, Cre-positive cells are expected to express GFP that can be tracked by green fluorescence $(69,70)$ (Fig. 2B). Should TGCTs not occur in these mice, efforts will be undertaken to investigate how interactions between Sertoli cells and Leydig cells contribute to the formation of TGCTs in the context of TGFBR1 activation (Fig. 2B).

In some genetically modified mouse models, GCTs occur in both males and females. Since there are both histopathological and molecular similarities between ovarian and testicular GCTs, it will be informative to perform comparative analyses of the tumor transcriptome/proteome between males and females. Commonly regulated genes are likely to be valuable candidates for investigating tumor etiology and treatment.

Although the FOXL2 mutation is a hallmark of adult ovarian GCTs (33), this mutation has only been analyzed in a small population of patients with TGCTs (39). Thus, the significance of this mutation in TGCTs remains unclear. Studies assessing the FOXL2 mutation in TGCTs in more patients, either retrospectively or prospectively, appear necessary in the future.

The pathogenesis of TGCTs is complex and involves multiple signaling pathways, including, but not limited to, 
WNT, KRAS and TGF $\beta$. In the TGFBR1-CA mouse model, activation of WNT signaling (12), PI3K/AKT signaling and extracellular signal-regulated kinase 1/2 (ERK1/2) singling pathways in TGCTs (Fang and Li, unpublished data) was found. A number of questions remain with regard to how these signaling pathways alter the identity of Sertoli cells and promote oncogenic transformation, whether there is crosstalk between these signaling branches, what the convergence points of these pathways are in the development of TGCTs, and how genetic factors, if any, impact cellular properties and outputs of signaling pathways in the process of tumorigenesis. Future studies that address these questions using new mouse models, as well as mathematical modeling $(71,72)$, will help our understanding of the pathogenesis of TGCTs and will guide the design of new therapies for this type of rare tumor.

\section{Acknowledgements}

The authors would like to thank Ms. Nan Ni (Texas A\&M University, College Station, TX, USA) for providing editorial assistance.

\section{Funding}

Research in the Li laboratory at Texas A\&M University (College Station, TX, USA) for granulosa cell tumors is supported by the National Cancer Institute of the National Institutes of Health under award number R03CA235001. The funding agency plays no role in literature analysis and interpretation and manuscript preparation.

\section{Availability of data and materials}

Not applicable.

\section{Author's contributions}

$\mathrm{XF}$ and QL analyzed the literature and wrote the manuscript. All authors read and approved the final manuscript.

\section{Ethics approval and consent to participate}

Not applicable.

\section{Patient consent for publication}

Not applicable.

\section{Competing interests}

The authors declare that they have no competing interests.

\section{References}

1. Scully RE: Ovarian tumors. A review. Am J Pathol 87: 686-720, 1977.

2. Sakr S, Abdulfatah E, Thomas S, Al-Wahab Z, Beydoun R, Morris R, Ali-Fehmi R and Bandyopadhyay S: Granulosa cell tumors: Novel predictors of recurrence in early-stage patients. Int J Gynecol Pathol 36: 240-252, 2017.

3. Colombo N, Parma G, Zanagnolo V and Insinga A: Management of ovarian stromal cell tumors. J Clin Oncol 25: 2944-2951, 2007.
4. Jamieson S and Fuller PJ: Molecular pathogenesis of granulosa cell tumors of the ovary. Endocr Rev 33: 109-144, 2012.

5. Vassal G, Flamant F, Caillaud JM, Demeocq F, Nihoul-Fekete C and Lemerle J: Juvenile granulosa cell tumor of the ovary in children: A clinical study of 15 cases. J Clin Oncol 6: 990-995, 1988.

6. Nasu K, Fukuda J, Yoshimatsu J, Takai N, Kashima K and Narahara H: Granulosa cell tumor associated with secondary amenorrhea and serum luteinizing hormone elevation. Int J Clin Oncol 12: 228-230, 2007.

7. Szewczuk W, Szewczuk O, Czajkowski K, Grala B and Semczuk A: Ovarian adult-type granulosa cell tumor concomitant with simple endometrial hyperplasia: A case study with selected immunohistochemistry. J Int Med Res 300060519886984, 2019 (Epub ahead of print).

8. Levin G, Zigron R, Haj-Yahya R, Matan LS and Rottenstreich A: Granulosa cell tumor of ovary: A systematic review of recent evidence. Eur J Obstet Gynecol Reprod Biol 225: 57-61, 2018.

9. Schumer ST and Cannistra SA: Granulosa cell tumor of the ovary. J Clin Oncol 21: 1180-1189, 2003.

10. Roth LM, Lyu B and Cheng L: Perspectives on testicular sex cord-stromal tumors and those composed of both germ cells and sex cord-stromal derivatives with a comparison to corresponding ovarian neoplasms. Hum Pathol 65: 1-14, 2017.

11. Young RH: Sex cord-stromal tumors of the ovary and testis: Their similarities and differences with consideration of selected problems. Mod Pathol 18 (Suppl 2): S81-S98, 2005.

12. Fang X, Ni N, Gao Y, Vincent DF, Bartholin L and Li Q: A novel mouse model of testicular granulosa cell tumors. Mol Hum Reprod 24: 343-356, 2018.

13. Cheng L, Albers P, Berney DM, Feldman DR, Daugaard G, Gilligan T and Looijenga LHJ: Testicular cancer. Nat Rev Dis Primers 4: 29, 2018

14. Moch H, Cubilla AL, Humphrey PA, Reuter VE and Ulbright TM: The 2016 WHO classification of tumours of the urinary system and male genital organs-Part A: Renal, penile, and testicular tumours. Eur Urol 70: 93-105, 2016.

15. Idrees MT, Ulbright TM, Oliva E, Young RH, Montironi R, Egevad L, Berney D, Srigley JR, Epstein JI and Tickoo SK; Members of the International Society of Urological Pathology Testicular Tumour Panel: The World Health Organization 2016 classification of testicular non-germ cell tumours: A review and update from the International Society of Urological Pathology Testis Consultation Panel. Histopathology 70: 513-521, 2017.

16. Al-Agha OM and Axiotis CA: An in-depth look at Leydig cell tumor of the testis. Arch Pathol Lab Med 131: 311-317, 2007.

17. Kim I, Young RH and Scully RE: Leydig cell tumors of the testis. A clinicopathological analysis of 40 cases and review of the literature. Am J Surg Pathol 9: 177-192, 1985.

18. Boyer A, Paquet M, Lague MN, Hermo L and Boerboom D: Dysregulation of WNT/CTNNB1 and PI3K/AKT signaling in testicular stromal cells causes granulosa cell tumor of the testis. Carcinogenesis 30: 869-878, 2009.

19. Richards JS, Fan HY, Liu Z, Tsoi M, Lague MN, Boyer A and Boerboom D: Either Kras activation or Pten loss similarly enhance the dominant-stable CTNNB1-induced genetic program to promote granulosa cell tumor development in the ovary and testis. Oncogene 31: 1504-1520, 2012.

20. Zugor V, Labanaris AP, Witt J, Seidler A, Weingartner K and Schott GE: Congenital juvenile granulosa cell tumor of the testis in newborns. Anticancer Res 30: 1731-1734, 2010.

21. Kao CS, Cornejo KM, Ulbright TM and Young RH: Juvenile granulosa cell tumors of the testis: A clinicopathologic study of 70 cases with emphasis on its wide morphologic spectrum. Am J Surg Pathol 39: 1159-1169, 2015.

22. Raju U, Fine G, Warrier R, Kini R and Weiss L: Congenital testicular juvenile granulosa cell tumor in a neonate with $\mathrm{X} / \mathrm{XY}$ mosaicism. Am J Surg Pathol 10: 577-583, 1986.

23. Young RH, Lawrence WD and Scully RE: Juvenile granulosa cell tumor-another neoplasm associated with abnormal chromosomes and ambiguous genitalia. A report of three cases. Am J Surg Pathol 9: 737-743, 1985.

24. Wu JT, Book L and Sudar K: Serum alpha fetoprotein (AFP) levels in normal infants. Pediatr Res 15: 50-52, 1981.

25. Dieckmann KP, Bertolini J and Wulfing C: Adult granulosa cell tumor of the testis: A case report with a review of the literature. Case Rep Urol 2019: 7156154, 2019.

26. Cornejo KM and Young RH: Adult granulosa cell tumors of the testis: A report of 32 cases. Am J Surg Pathol 38: 1242-1250, 2014. 
27. Jimenez-Quintero LP, Ro JY, Zavala-Pompa A, Amin MB Tetu B, Ordonez NG and Ayala AG: Granulosa cell tumor of the adult testis: A clinicopathologic study of seven cases and a review of the literature. Hum Pathol 24: 1120-1125, 1993.

28. Suppiah A, Musa MM, Morgan DR and North AD: Adult granulosa cell tumour of the testis and bony metastasis. A report of the first case of granulosa cell tumour of the testicle metastasising to bone. Urol Int 75: 91-93, 2005

29. Hanson JA and Ambaye AB: Adult testicular granulosa cell tumor: A review of the literature for clinicopathologic predictors of malignancy. Arch Pathol Lab Med 135: 143-146, 2011.

30. Pisarska MD, Barlow G and Kuo FT: Minireview: Roles of the forkhead transcription factor FOXL2 in granulosa cell biology and pathology. Endocrinology 152: 1199-1208, 2011

31. Uhlenhaut NH, Jakob S, Anlag K, Eisenberger T, Sekido R, Kress J, Treier AC, Klugmann C, Klasen C, Holter NI, et al: Somatic sex reprogramming of adult ovaries to testes by FOXL2 ablation. Cell 139: 1130-1142, 2009.

32. Kalfa N, Fellous M, Boizet-Bonhoure B, Patte C, Duvillard P, Pienkowski C, Jaubert F, Ecochard A and Sultan C: Aberrant expression of ovary determining gene FOXL2 in the testis and juvenile granulosa cell tumor in children. J Urol 180 (Suppl 4) S1810-S1813, 2008.

33. Shah SP, Kobel M, Senz J, Morin RD, Clarke BA, Wiegand KC, Leung G, Zayed A, Mehl E, Kalloger SE, et al: Mutation of FOXL2 in granulosa-cell tumors of the ovary. N Engl J Med 360: 2719-2729, 2009

34. Nonis D, McTavish KJ and Shimasaki S: Essential but differential role of FOXL2wt and FOXL2C134W in GDF-9 stimulation of follistatin transcription in co-operation with Smad3 in the human granulosa cell line COV434. Mol Cell Endocrinol 372: 42-48, 2013.

35. Cheng JC, Chang HM, Qiu X, Fang L and Leung PC: FOXL2-induced follistatin attenuates activin A-stimulated cell proliferation in human granulosa cell tumors. Biochem Biophys Res Commun 443: 537-542, 2014.

36. Leung DTH, Fuller PJ and Chu S: Impact of FOXL2 mutations on signaling in ovarian granulosa cell tumors. Int J Biochem Cell Biol 72: 51-54, 2016

37. Kim JH, Yoon S, Park M, Park HO, Ko JJ, Lee K and Bae J Differential apoptotic activities of wild-type FOXL2 and the adult-type granulosa cell tumor-associated mutant FOXL2 (C134W). Oncogene 30: 1653-1663, 2011.

38. Fleming NI, Knower KC, Lazarus KA, Fuller PJ, Simpson ER and Clyne CD: Aromatase is a direct target of FOXL2: C134W in granulosa cell tumors via a single highly conserved binding site in the ovarian specific promoter. PLoS One 5: e14389, 2010.

39. Lima JF, Jin L, de Araujo AR, Erikson-Johnson MR, Oliveira AM, Sebo TJ, Keeney GL and Medeiros F: FOXL2 mutations in granulosa cell tumors occurring in males. Arch Pathol Lab Med 136: 825-828, 2012.

40. Fuller PJ, Chu S, Fikret S and Burger HG: Molecular pathogenesis of granulosa cell tumours. Mol Cell Endocrinol 191: 89-96, 2002.

41. Kim SY: Insights into granulosa cell tumors using spontaneous or genetically engineered mouse models. Clin Exp Reprod Med 43: 1-8, 2016

42. Matzuk MM, Finegold MJ, Su JG, Hsueh AJ and Bradley A: Alpha-inhibin is a tumour-suppressor gene with gonadal specificity in mice. Nature 360: 313-319, 1992

43. Li Y, Zhang L, Hu Y, Chen M, Han F, Qin Y, Chen M, Cui X, Duo $\mathrm{S}$, Tang $\mathrm{F}$ and Gao F: $\beta$-Catenin directs the transformation of testis Sertoli cells to ovarian granulosa-like cells by inducing Fox12 expression. J Biol Chem 292: 17577-17586, 2017.

44. Pangas SA, Li X, Umans L, Zwijsen A, Huylebroeck D, Gutierrez C, Wang D, Martin JF, Jamin SP, Behringer RR, et al: Conditional deletion of Smad1 and Smad5 in somatic cells of male and female gonads leads to metastatic tumor development in mice. Mol Cell Biol 28: 248-257, 2008

45. Ying SY: Inhibins, activins, and follistatins: Gonadal proteins modulating the secretion of follicle-stimulating hormone. Endocr Rev 9: 267-293, 1988.

46. O'Connor AE and De Kretser DM: Inhibins in normal male physiology. Semin Reprod Med 22: 177-185, 2004.

47. Kumar TR, Wang Y and Matzuk MM: Gonadotropins are essential modifier factors for gonadal tumor development in inhibin-deficient mice. Endocrinology 137: 4210-4216, 1996.

48. Cipriano SC, Chen L, Burns KH, Koff A and Matzuk MM Inhibin and p27 interact to regulate gonadal tumorigenesis. Mol Endocrinol 15: 985-996, 2001 .
49. Burns KH, Agno JE, Sicinski P and Matzuk MM: Cyclin D2 and p27 are tissue-specific regulators of tumorigenesis in inhibin alpha knockout mice. Mol Endocrinol 17: 2053-2069, 2003.

50. Li Q, Graff JM, O'Connor AE, Loveland KL and Matzuk MM: SMAD3 regulates gonadal tumorigenesis. Mol Endocrinol 21: 2472-2486, 2007.

51. Klaus A and Birchmeier W: Wnt signalling and its impact on development and cancer. Nat Rev Cancer 8: 387-398, 2008.

52. Boerboom D, Paquet M, Hsieh M, Liu J, Jamin SP, Behringer RR, Sirois J, Taketo MM and Richards JS: Misregulated Wnt/beta-catenin signaling leads to ovarian granulosa cell tumor development. Cancer Res 65: 9206-9215, 2005.

53. Mitsiades CS, Mitsiades N and Koutsilieris M: The Akt pathway: Molecular targets for anti-cancer drug development. Curr Cancer Drug Targets 4: 235-256, 2004.

54. Hay N: The Akt-mTOR tango and its relevance to cancer. Cancer Cell 8: 179-183, 2005.

55. Haigis KM: KRAS alleles: The devil is in the detail. Trends Cancer 3: 686-697, 2017.

56. Fan HY, Shimada M, Liu Z, Cahill N, Noma N, Wu Y, Gossen J and Richards JS: Selective expression of KrasG12D in granulosa cells of the mouse ovary causes defects in follicle development and ovulation. Development 135: 2127-2137, 2008

57. Hannenhalli S and Kaestner KH: The evolution of Fox genes and their role in development and disease. Nat Rev Genet 10: 233-240, 2009

58. Uhlenhaut NH and Treier M: Forkhead transcription factors in ovarian function. Reproduction 142: 489-495, 2011.

59. Belli M, Secchi C, Stupack D and Shimasaki S: FOXO1 negates the cooperative action of FOXL2 ${ }^{\mathrm{C} 134 \mathrm{~W}}$ and SMAD3 in CYP19 expression in $\mathrm{HGrC1}$ cells by sequestering SMAD3. J Endocr Soc 3: 2064-2081, 2019.

60. Liu Z, Ren YA, Pangas SA, Adams J, Zhou W, Castrillon DH, Wilhelm D and Richards JS: FOXO1/3 and PTEN depletion in granulosa cells promotes ovarian granulosa cell tumor development. Mol Endocrinol 29: 1006-1024, 2015.

61. Massague J: TGF-beta signal transduction. Annu Rev Biochem 67: 753-791, 1998

62. Fang X, Gao Y and Li Q: SMAD3 activation: A converging point of dysregulated TGF-Beta superfamily signaling and genetic aberrations in granulosa cell tumor development? Biol Reprod 95: 105, 2016

63. Massague J: TGFbeta in cancer. Cell 134: 215-230, 2008

64. Gao Y, Vincent DF, Davis AJ, Sansom OJ, Bartholin L and Li Q Constitutively active transforming growth factor $\beta$ receptor 1 in the mouse ovary promotes tumorigenesis. Oncotarget 7 : 40904-40918, 2016.

65. Boyer A, Hermo L, Paquet M, Robaire B and Boerboom D Seminiferous tubule degeneration and infertility in mice with sustained activation of WNT/CTNNB1 signaling in sertoli cells. Biol Reprod 79: 475-485, 2008

66. Jamin SP, Arango NA, Mishina Y, Hanks MC and Behringer RR: Requirement of Bmprla for Mullerian duct regression during male sexual development. Nat Genet 32: 408-410, 2002.

67. Tanwar PS, Kaneko-Tarui T, Zhang L, Rani P, Taketo MM and Teixeira J: Constitutive WNT/beta-catenin signaling in murine Sertoli cells disrupts their differentiation and ability to support spermatogenesis. Biol Reprod 82: 422-432, 2010.

68. Albrecht KH and Eicher EM: Evidence that Sry is expressed in pre-Sertoli cells and Sertoli and granulosa cells have a common precursor. Dev Biol 240: 92-107, 2001

69. Muzumdar MD, Tasic B, Miyamichi K, Li L and Luo L: A global double-fluorescent Cre reporter mouse. Genesis 45: 593-605, 2007.

70. Snyder CS, Harrington AR, Kaushal S, Mose E, Lowy AM, Hoffman RM and Bouvet M: A dual-color genetically engineered mouse model for multispectral imaging of the pancreatic microenvironment. Pancreas 42: 952-958, 2013.

71. Gammon K: Mathematical modelling: Forecasting cancer. Nature 491: S66-S67, 2012

72. Beerenwinkel N, Schwarz RF, Gerstung M and Markowetz F: Cancer evolution: Mathematical models and computational inference. Syst Biol 64: e1-e25, 2015.

This work is licensed under a Creative Commons Attribution-NonCommercial-NoDerivatives 4.0 International (CC BY-NC-ND 4.0) License. 